\title{
Forma e substância do texto jurídico*
}

\author{
Form and substance of the legal text
}

\section{Carlos Petit**}

\section{REFERÊNCIA}

PETIT, Carlos. Forma e substância do texto jurídico. Revista da Faculdade de Direito da UFRGS, Porto Alegre, n. 46, p. 53-70, ago. 2021. DOI: https://doi.org/10.22456/0104-6594.117987.

\section{RESUMO}

As linhas que se seguem têm a modesta finalidade de chamar a atenção dos pesquisadores interessados em história do direito quanto a algumas questões prévias ao aproveitamento das fontes. Sendo estas, geralmente, documentos escritos e, com frequência, impressos. É grande a tentação a lançar-se à sua leitura e a utilizar no trabalho as muitas notícias que contêm. Todavia, os textos se apresentam sob múltiplas formas e maneiras, e deter-se por um momento quanto a considerar as suas características externas talvez ajude a melhorar sua leitura. Entendendo, também, que as circunstâncias puramente formais oferecem um argumento idôneo que merece pesquisa.

\section{PALAVRAS-CHAVE}

História do Direito. História dos impressos. Periodismo jurídico. Meios de comunicação do Direito.

\begin{abstract}
The following lines have the modest purpose of drawing the attention of researchers interested in Legal History to some issues prior to the use of sources. These sources are usually written documents and, frequently, prints. It is a great temptation for researchers to start reading them and to use in their work the variety of content found. However, texts are presented in many forms and shapes, and taking a moment to consider external characteristics may improve their reading. We may understand, as well, that the purely formal circumstances offer a reputable argument worth investigating.
\end{abstract}

\section{KEYWORDS}

Legal history. History of prints. Legal reviews. Media of Law.

\footnotetext{
* Publicação original do texto em língua espanhola: PETIT, Carlos. Forma y sustancia del texto jurídico. In: NAVARRO, Mónica P. F. (ed.). Derecho, memoria e historia en Hispanoamérica. Bogotá: Universidad Libre, 2018. p. 269-289. Tradução para a língua portuguesa de Frederico Paganin Gonçalves (Graduando na Faculdade de Direito da UFRGS). Revisão da tradução por Alfredo de J. Flores (Professor Permanente do PPGD-UFRGS). Os tradutores agradecem a autorização dada pelo autor.

** Licenciado (1977) e doutor em Direito pelas Universidades de Sevilla (1979) e Bologna (1985). Licenciado em Geografia e História (especialidade: História) pela Universidade de Sevilla (1988), professor titular na Universidade de Sevilla (1983-1986), catedrático na Universidade Autônoma de Barcelona (1986-1998), catedrático na Universidade de Huelva (1988-), desde 1994 vem sendo professor visitante em várias universidades da Europa e América. Tem publicado recentemente importantes textos como: Historia del Derecho Mercantil (Madrid: Marcial Pons, 2016); Fiesta y contrato: Negocios taurinos em protolocos sevillanos, 1777-1847 (Madrid: Universidad Carlos III - Editorial Dykinson, 2011); Rafael de Ureña. La legislación gótico-hispana (ed. Carlos Petit. Pamplona: Urgoiti, 2003); Ivstitia gothica: Historia social y teología del proceso en la Lex Visigothorum (Huelva: Universidad de Huelva, 2001); Max Radin. Cartas romanísticas, 1923-1950 (Estudo e edição, com uma nota de leitura sobre "California y el Derecho romano" por Carlos Petit. Napoli: Jovene Editore, 2001); Discurso sobre el discurso: Oralidad y escritura en la cultura jurídica en la España liberal (Huelva: Universidad de Huelva, 2000).
} 


\section{SUMÁRIO}

1. Introdução. 2. Scriptura non est de esse legis. 3. Oralidade e escritura na cultura jurídica liberal. 4. Do volume ao codex: substância jurídica da filologia formal. 5. O "efeito biblioteca". 6. O tamanho do direito. 7. O tempo e os textos. Referências. Dados da publicação.

\section{INTRODUÇÃO}

As linhas que se seguem têm a modesta finalidade de chamar a atenção dos pesquisadores interessados em história do direito ${ }^{1}$ quanto a algumas questões prévias ao aproveitamento das fontes. Sendo estas, geralmente, documentos escritos e, com frequência, impressos. É grande a tentação a lançar-se à sua leitura e a utilizar no trabalho as muitas notícias que contêm. Todavia, os textos se apresentam sob múltiplas formas e maneiras, e deter-se por um momento quanto a considerar as suas características externas talvez ajude a melhorar sua leitura. Entendendo, também, que as circunstâncias puramente formais oferecem um argumento idôneo que merece pesquisa.

Nessas matérias, a utilidade da frondosa literatura sobre história do livro e da leitura é, infelizmente, reduzida. Pode-se dizer que os jurídicos têm apenas suscitado interesse dos estudiosos.

Pelo contrário, agora se parte da singularidade dos textos de direito, enquanto frutos de um saber consolidado que se manifestou em gêneros literários específicos - pensemos nas coleções de decisões dos altos tribunais do Antigo Regime, nos pareceres e consultas dos juristas, em suas glosas e comentários às principais compilações - e circulou por circuitos próprios, isto é, não recorridos por obras de natureza distinta. Ainda que venhamos a contar com aportes da maior valia, o espaço para mais contribuições está aberto².

\footnotetext{
${ }^{1}$ Devido ao amável convite de Mónica Fortich, da Universidad Libre (Bogotá), publico a minha intervenção no "II Encuentro Internacional de Historiografía, Sociología y Cultura Jurídica - VI Encuentro del Instituto Colombiano de Historia del Derecho". Deve-se à insistência de Mónica também a redação, anotada, de minha intervenção verbal, à qual não havia previsto. Porém, sobre essas coisas, diz-se algo mais nas páginas que seguem.

${ }^{2}$ Hespanha (2008). Este autor tem orientado também nesse mesmo sentido ("law as a communicative system") sua notável contribuição - ainda em curso de impressão - para o Oxford Handbook of European Legal History (Heikki Pihlajamäki, Markus Dubber, Mark Godfrey eds.). [Nota de tradução: o texto consta publicado agora em: HESPANHA, António Manuel. Southern Europe (Italy, Iberian Peninsula, France). In: PIHLAJAMÄKI, H.; DUBBER, M.; GODFREY, M. (eds.). Oxford Handbook of European Legal History. Oxford: Oxford University Press, 2018].
} 


\section{SCRIPTURA NON EST DE ESSE LEGIS}

Segue uma primeira questão: devemos aceitar, sem mais, que o texto jurídico é sempre um discurso posto por escrito? A pergunta remete a um tópico doutrinário debatido com intensidade nos momentos áureos do ius commune, mas resulta pertinente para utilizar muitos documentos produzidos nos tempos recentes de cultura "liberal".

Em 1873, a Rota Pontifícia, tendo por fim regressado a Roma, resolveu um assunto em que o ponto controverso consistia na escritura ou na condição verbal da norma aplicável ${ }^{3}$. Trata-se de uma decisio nova da coleção que veio a ser impressa em 1555, ditada por um juiz da Rota - provavelmente assessorado por seus outros colegas -, da qual só conhecemos a parte dispositiva; segundo o que preocupava por então aos magistrados, o caso seguramente teria relação com a atribuição de um benefício eclesiástico que era disputado entre dois clérigos sobre a base de algum acordo capitular não escrito.

O desconhecido autor da decisão cita os clássicos do Comentário (Giovanni d'Andrea, Pierre de Belleperche, Guido de Baisio) e vários extratos do Código de Justiniano e das Decretais para concluir - com os restantes juízes da Rota - que "constitutio sive statutum canonicorum sive capituli protest probari per testes: quia scriptura non est de esse sive substantia legis vel constitutionis".

A solução estava longe de ser algo evidente. Como será recordado, as Institutiones justinianeias expressam a distinção entre ius scriptum e ius non scriptum (1.2.3; 1.2.9), reservando a segunda categoria para o costume; ademais, antigas e veneradas obras gerais basta pensar nas Etymologiae de Isidoro de Sevilha - haviam relacionado o termo-conceito lex com a possibilidade de leitura (lex a legendo), tal como reconhecia Guido de Baisio (ca. 1250-1313), citado na decisio.

Porém também se sabia que a vontade do príncipe, independentemente de seus modos de expressão, tinha força de lei (“quod principi placuit...”, D 1.4.1), o que valia, em particular, para as decisões normativas do Papa, válidas em qualquer caso: "sive quae scriptuo decrevimus, sive quae in mostra praesentia videntur esse disposita" (Dec. Grat., C. 25 q. 2).

\footnotetext{
${ }^{3}$ Para o que segue, Dolezalek (1980, p. 48-70). Porém, também, apesar do amigo Dolezalek (conferir p. 52, n. 3), interessa Cortese (1964, rist. 1995, p. 355 et seq.). 
Várias normas canônicas compiladas, recordadas pela Rota de modo oportuno, insistiam, por sua vez, na insubstancialidade da escritura para entender válida uma "lei"4. Pois, não foi habitual na pontifícia e universitária cidade de Bolonha que o legado papal que a governava promulgasse normas de viva voz? ${ }^{5}$ A forma escrita da "lei”" poderia, em conclusão, ser útil para efeitos probatórios, mas também valia nessa matéria a prova de testemunhas.

Admitida a validade da "lei" não escrita, um célebre jurista entendeu que os efeitos daquela que fosse simplesmente anunciada por pregão ficariam em nada, por faltar um conhecimento cabal dos submetidos ao seu mandato; porém, este não é do interesse do presente trabalho ${ }^{6}$. O recordado até agora basta para chamar a atenção sobre o problema de textos jurídicos que hoje podem ser lidos, ainda que, em si, nunca tenham sido escritos antes.

\section{ORALIDADE E ESCRITURA NA CULTURA JURÍDICA LIBERAL}

Por mais estranha que pareça a proposição anterior, o certo é que contamos com numerosos documentos que, mesmo que ligeiramente estudados, mostram-se como o escrito precipitado de um momento verbal precedente. Pensamos na maior parte dos manuais jurídicos publicados na Espanha liberal, nascidos de notas de aulas, mais ou menos revisadas pelo titular do curso, tomadas pelos próprios estudantes: "fielmente copiadas" - manifesta um deles (1849) - “em virtude do excelente método que existe em nossas aulas, de apontamentos feitos pelos alunos sobre a explicação do professor"?

\footnotetext{
${ }^{4}$ Convém introduzir outra cautela, entre formal e substancial, referente à tradução do texto jurídico; por exemplo, o conceito de lex não pode ser ligeiramente traduzido por lei, por respeito à diversidade, tão marcada, de sentidos e critérios de produção. Na cultura do ius commune - que mantém a tradição romano-cristã dos livros normativos visigodos - entendia-se a lex como um mandato derivado da divindade ("lex est sanctio sancta") ou da natureza ("lex est ratio insita nature"), fruto do consenso entre os fideles ("lex est commune praeceptum"); sem relação particular, como vemos, com os desígnios de uma potestade humana concreta; outros atos de relevância jurídica - um testamento, uma sentença judicial, um contrato - também poderiam ser leges: e, sem dúvida, essa antiga ideia esteve presente quando o codificador napoleônico estabeleceu que "[1]es conventions légalement formées tiennent lieu de loi à ceux qui les ont faites" (art. 1134, Code civil). Cf. Cortese (Norma giuridica I, p. 293 et seq.; II, p. 83, p. 242); também Vallejo (1992, p. 315 et seq.), sobre o conditor legum como um legum interpres.

${ }^{5}$ Dolezalek (p. 63 et seq.) edita duas quaestiones mais de um século antes - coisas dos canonistas Juan de Dios (Iohannes de Deo) e Stephan Polonus - a propósito de uma Constituição não escrita do legado pontifício na Romana apontando a pena de excomunhão para o eclesiástico que concedera ou aceitara um benefício sem cumprir com o dever de residência.

${ }^{6}$ Dolezalek (p. 61 et seq.), sobre a opinião de Baldo favorável à escritura (“Ioannes Andreae dicit quod non requiritur ad primordiale esse, sed ad observantiam esse. Nisi enim interuenerit scriptura, non possent publicari, nec innotescere populo, presertim his qui tempore statuti conditi non erant in rerum natura. Et ideo frustra fierrent, quia non ligarent").

${ }^{7}$ Laso (1849, p. V-VI). Contudo, conservamos, além de Laso, as notas de aula: Ensayo de Jurisprudencia mercantil, que dedica á sus amados Discípulos el Profesor de 3er. año en la Universidad de Madrid [1847], ms.
} 
Se cotejamos ambas as versões do livro, a inédita-espontânea e a pública-reelaborada, resulta possível nos aprofundarmos não somente em aspectos fundamentais (da história) da docência de Direito - tão permeada pelos atos verbais: exames, lições, colações de grau... com marcas específicas da "oratória do foro"8 -, mas também na complicada passagem da palavra jurídica ao texto escrito, seja de caráter acadêmico, parlamentar ou processual ${ }^{9}$.

Denunciam a origem verbal dos discursos - quando não o confessa uma "Advertência sem paginar" ou outro paratexto parecido - o uso do vocativo (prova da existência de um auditório histórico, que também se faz ver no texto, com notas como "aplausos", "protestos", "murmúrios"), a recapitulação do que "se dizia ontem" ao passar de capítulo, a sintaxe incorreta de um período ou frase em uma intervenção que também comunicava com o gesto e a entonação, os tropos alusivos, a ausência de autoridades (apenas citadas, e não somente nem principalmente jurídicas).

A fonte principal do Direito - refiro-me à lei estatal - também esteve permeada de experiências orais, como as exposições de motivos: um catálogo de tópicos persuasivos, herança de tempos passados, quando o destinatário da norma dispunha de recursos "obedece-se, mas não se cumpre" - para obstar o seu mandato. Quanto ao restante, a lei foi, a um tempo, objeto e fruto de debates, cujo conhecimento há de permitir sua melhor interpretação.

Desde o ponto de vista das consignas da investigação, resulta fundamental identificar a natureza oral do texto, pois a palavra dita e a escrita respondem a regras de composição e, portanto, de compressão, em tudo diferentes. Assim, frequentemente são tachadas como irrelevantes as "teses" defendidas na universidade - não somente espanhola - do século XIX,

conservado na Biblioteca Nacional (Madrid), signatura 5662. E foi um modo habitual de proceder: conhecemos também que: "las lecciones de Historia de la legislación española, que el antiguo catedrático de Alcalá, don Eustoquio Laso, autor de un extenso tratado de Derecho mercantil... han sido coleccionadas con esmero y buen orden por uno de sus más aventajados discípulos... Los estudiantes se ahorrarán con el compendio del señor Bañares el trabajo de escribir las conferencias de su maestro, quien le ha revisado y aprobado previamente" (cf. La España, Madrid, 17 de novembro, 1860, p. 1).

${ }^{8}$ Tive acesso a um programa inédito do catedrático Manuel López Gómez (1823-1883), da Universidade de Valladolid, custodiado em seu expediente pessoal: Archivo General de la Administración (Alcalá de Henares, Madrid), seção Educación, caj. 31/16059. Disposto em sessenta e nove lições, contém enunciados do tipo seguinte: "Lección 10. Medios que pueden emplearse para encontrar novedad en los pensamientos. Uso de los tropos a este fin. Regla para el empleo en composiciones literarias, de los pensamientos analizados en la lección anterior...Lección 41. Dotes y preparación del orador forense. Dotes naturales del orador. Sus cualidades morales... Lección 60. Elocuencia patética y su lugar en los discursos forenses. Examen de las opiniones de Quintiliano, Cicerón, la Harpa, Blair y otros”. Como manual do tema, de existência episódica nos planos de estudo liberais, Sauri y Lleopart (1847).

${ }^{9}$ Petit (2014, p. 110 et seq.). 
esquecendo-se ou desconhecendo sua autêntica natureza. Isto é, simples orações cerimoniais declamadas no momento solene da recepção das insígnias de graduação, sem outra pretensão que a de mostrar a corporação acadêmica ante o público e as autoridades do Estado.

Com essa classe de juízos precipitados, desconhece-se, ademais, que a ciência, entendida como propósito dos institutos de educação superior, somente é documentada nas disposições espanholas ${ }^{10}$ a partir dos anos 1880. Seria um péssimo proceder lamentar pelo que não chegou a existir: assim, por exemplo, uma teoria (como a alemã) do direito público omitindo que ninguém pretendia então que viesse a existir; ao invés de observar, sem preconceitos, o quanto aportou de maneira positiva a cultura passada - o direito político, no caso citado - e tornaram possíveis suas próprias circunstâncias ${ }^{11}$.

\section{DO VOLUME AO CODEX: SUBSTÂNCIA JURÍDICA DA FILOLOGIA FORMAL}

A escrita se entendeu, em conclusão, como acidente do discurso jurídico. Situados ante um discurso já recolhido por escrito, o segundo passo na pesquisa consiste em analisá-los enquanto artefatos físicos.

A antiguidade conheceu duas modalidades principais para compor, conservar e transmitir os textos. A primitiva foi o volumen, livro cilíndrico enformado por tiras de material vegetal (talhos de papiro: a flor do rei, como diziam os egípcios) enroladas em torno de um eixo vertical que fosse suscetível de recolher, em seções de dimensão regular, as linhas de um texto em uma sequência de parágrafos paralelos; daí procede uma das habituais divisões que ainda empregamos em nossa cultura literária.

A partir do século III de nossa era, abriu-se o passo para outra classe de livro: o codex, derivado do uso de pequenas tábuas enceradas (por caudex, córtex de árvore: "ex quo cortex extrahitur"), compostas de folhas recortadas em dimensões iguais, costuradas ou coladas pela margem esquerda, conformando um ortoedro; assim, a progressiva imposição do codex texto mais robusto e de leitura mais simples que o volumen - permitiu a generalização do pergaminho como material para escrever, sendo uma fina membrana de pele animal que poderia ser utilizada mais de uma vez, quando apagada a primeira escritura.

\footnotetext{
${ }^{10}$ Petit (1997, p. 593-614).

11 Pela razão alegada, não compartilho do enfoque de Gallego Anabitarte (2002), ainda que repleto de informações.
} 
Inicialmente, esse novo formato foi reservado aos textos da religião cristã e aos jurídicos, ambos complexos, destinados a uma leitura per saltum, permeados de autoridade. Ao longo do século IV, tomou lugar um lento processo de edição e transferência da literatura pagã dos antigos volumina aos novos códices... no que se perderam muitos textos pelo caminho $^{12}$.

Uma notável transformação nas fontes do direito romano coincidiu com as mudanças na forma dos livros. Desde o século I vinha crescendo o ius novum das constituições ou normas estabelecidas pelo imperador no uso de suas magistraturas (edicta, decreta, rescripta...), objeto de coleção ordenada - para o estudo e aplicação judicial - justamente quando se elaboram livros-códices de forma habitual. Corresponde a esse ambiente o chamado Codex Gregorianus, com textos de (provavelmente) Adriano (76-138) a Diocleciano (244-311), sob cujo reinado foi compilado, e o Codex Hermogenianus, que reunia constituições deste imperador e de seus imediatos sucessores, concebido como continuação do primeiro.

Apesar de sua transmissão fragmentária, conhecemos as divisões internas desses Códices, o que permite identificar certos critérios de ordenação interior que vieram a ter muito sucesso. Efetivamente, o Gregorianus se divide em libri-tituli-constitutiones, enquanto o Codex Hermogenianus era, em si, um liber singularis subdividido em tituli.

O sentido específico da voz liber aludia ao rolo de papiro que continha uma parte do texto; daí a sua extensão, para significar uma parte, distinta em razão da matéria, do livrocódex de conteúdo jurídico. Por sua vez, o termo titulus significava a epígrafe que introduzia as cláusulas de um ato de vontade última, pelo comum recolhida em duas pequenas tábulas enceradas, encerradas sobre os frontispícios escritos e selados ${ }^{13}$. Empregados em textos jurídicos, esses elementos de forma, não se estranhará que os mesmos acabassem compenetrados com a substância e servissem para designar, ao longo dos séculos, os cortes sistemáticos introduzidos na materia legalis ${ }^{14}$.

Se os exemplos anteriores explicam a nascente e duradoura "juridificação" do livrocodex (e ainda de seus derivados em línguas atuais: "código", "code", "codice”, "Kodex”),

\footnotetext{
${ }^{12}$ Da abundante bibliografia que ilustra essas transformações, ver Johannot (1994).

${ }^{13}$ D'Ors (1953, p. 495-514).

${ }^{14}$ Por exemplo, o Liber Iudiciorum (ou Lex Visigothorum, a. 654), tão influente na Idade Média hispana, dividese em 12 livros, subdivididos por sua vez em títulos compostos por aerae ou leges; porém, o modelo mais influente para as compilações jurídicas europeias da baixa Idade Média e da Moderna se encontrou no Liber Extra, principal coleção das decretais pontifícias extra Decretum Gratiani vagantium (a. 1234).
} 
também mostram as opções que se abriam frente aos editores antigos com a mudança do formato - o que deveria de passar com os novos textos; que respeito convinha manter ao teor original; que concessões teria ou não que fazer para renovar uma mensagem antiquada...; foram dúvidas cujas respostas condicionaram a tradição textual e, portanto, o quanto sabemos da experiência jurídica de Roma. Talvez convenha recordar que as Institutas de Gaio, por mais que em uma só cópia, tardia e torturada, são a única obra da jurisprudência clássica conservada à margem dos fragmentos manipulados do Digesto ${ }^{15}$.

De fato, a cópia massiva de obras obrigou a uma intensa seleção de textos dignos de serem "codificados" - outros muitos foram perdidos ou foram conservados somente em fragmentos - e a sua profunda reelaboração ${ }^{16}$. Perderam interesse as disputas doutrinais dos autores antigos. Adicionaram-se glosas e comentários, cuja identificação assinala um momento especial na investigação romanística ${ }^{17}$.

Peças mais complexas foram objeto de resumo e se evidenciaram as razões hipotéticas da decisão do jurista clássico. Alterou-se, por fim, o estilo das fontes e sua própria expressão. E, especialmente: na trilha da alteração formal, surgiram novos gêneros literários, como os epitomata: obras atribuídas a algum nome consagrado - nem sempre, ao menos não exclusivamente, o verdadeiro autor - que expunham de modo simples a matéria jurídica. Foi o caso das Pauli Sententiae, na melhor das hipóteses, elaboradas na segunda metade do século III com textos de Paulo, dentre outros, que conheceram ampla difusão no Ocidente.

\section{O "EFEITO BIBLIOTECA"}

A história do livro conhece outro momento decisivo quando, em meados do século XV e respeitando o formato consagrado, os manuscritos passaram a converter-se em textos policopiados pelo procedimento de impressão mecânica com tipos móveis; contudo, essa questão não nos deve ser motivo de distração ${ }^{18}$.

\footnotetext{
$15 \mathrm{O}$ descobrimento do Gaio de Verona foi a circunstância que determinou o auge internacional da ciência jurídica alemã até quase os nossos dias: cf. Vano (2000).

${ }^{16}$ Kaser (1967, p. 226 et seq.).

${ }^{17}$ Para o humanismo, cf. Palazzini Finetti (1953); em geral, Mitteis, Levy e Rabel (1929-1935).

18 Tampouco se fará a análise das pecias, procedimento inventado na universidade medieval para copiar agilmente os escritos de uso escolar: Soetermeer (1997).
} 
O amigo António Hespanha se ocupou de tal com solvência, e nossas linhas não saberiam aportar coisa de importância ${ }^{19}$. Ademais, qualquer que seja a sua forma, o livro se custodia junto com outros no âmbito de uma biblioteca. Analisar essa circunstância gregária, conhecer que títulos rodearam a obra de que nos interessa tratar, oferece outra linha de trabalho, sem dúvida prometedora, para penetrar no conhecimento da substância jurídica dos textos.

Adverte-se que o termo de referência apresenta vários significados, todos eles relevantes para os atuais propósitos desse trabalho. Existe, em primeiro lugar, a biblioteca entendida como um espaço destinado à conservação ordenada dos textos, cuja disposição dependeria do peso, culturalmente relativo, dos saberes colecionados: a maior ou menor proximidade do Direito à Religião, o número das estantes dedicadas a umas ou outras obras... são elementos visíveis que estimulam a mente do historiador ${ }^{20}$.

Por outro lado, o concerto material dos livros se replicou "virtualmente" em obras que responderam a uma segunda acepção do termo, nesse caso empregado para designar aqueles nutridos repertórios bibliográficos de corte local (Nicolás Antonio, Bibliotheca Hispana, 1672-1692; Diogo Barbosa Machado, Bibliotheca Lusitana, 1741-1758), corporativo (Philippe de Alegambe, Bibliotheca scriptorum Societatis lesu, 1643, continuação da obra homônima do padre Rivadeneyra, 1603) ou de conteúdo (Martin Lippenius, Bibliotheca realis iuridica, 1679; Agostino Fontana, Bibliotheca legalis amplissima, 1688; The Universal Library of Trade and Commerce, 1747), publicados na Europa do Antigo Regime; trata-se das que Roger Chartier qualificou com eficácia como "bibliotecas sem muros"21.

E é claro que o proveito que cabe esperar de sua consulta vai mais além de sua óbvia utilidade como lista de autores e títulos, pois essas "bibliotecas" respondiam a uma classificação dos conhecimentos cuja compreensão resulta inexcusável; por exemplo, qualquer interessado no regime dos contratos que vá à Bibliotheca do sevilhano Antonio não deve admirar-se ao comprovar que sua matéria se apresenta como uma subcategoria (“De

\footnotetext{
${ }^{19}$ Hespanha, 2008. Sobre o quadro geral, Eisenstein (1980).

${ }^{20}$ E contamos com aportes técnicos que ajudam muito nessa sorte de investigações: cf. Accaristi, Belotti (1984). Uma de suas ilustrações é uma gravura que representa a sala geral dos livros da Universidade de Leyden (1610): com seis estantes duplas dedicadas aos "Theologi" e cinco aos "Iurisconsulti", ambos ainda em feliz proximidade, obtemos uma precisa imagem da valoração concedida aos saberes (quatro mais dos "Historici", duas nos casos dos "Philosophi", "Literati" e "Medici", uma de "Mathematici").

${ }^{21}$ Chartier (1996, p. 107-131).
} 
iustitia et iure, et contractibus"), ${ }^{22}$ da seção dedicada à Teologia moral (VIII: "Moralia Theologica, Philosophica, seu Politico-moralia"), mostrando as coordenadas culturais e confessionais que enquadraram o direito das obrigações. A matéria (XV) de "Juridica, canonica, legalia, politico-legalia" inclui uma seção principal "De christiana republica et ejus regimine hierarchico", e mantém uma atenção às fontes canônicas e romanas e seus respectivos comentários que domina a consideração dos iura propria; a conclusão é clara: uma pesquisa conduzida sobre textos reinícolas haveria de começar por aquelas outras obras, aparentemente alheias aos objetos em estudo, que dotavam de sentido e fundamento as normas seculares do território.

Em uma terceira acepção, o termo biblioteca serve ainda para designar aquela coleção de livros reunida em série por algum desígnio editorial; nesses casos, o alcance de cada peça se altera quando damos entrada às demais incluídas na série que todas conformam ${ }^{23}$.

O "efeito biblioteca", assim entendido, desdobra-se em vários planos que cooperam em recíproca conotação das obras reunidas. Tratando-se frequentemente de traduções porém, ainda não o sendo, a identidade de formatos, paratextos, prólogos, índices... permitem o desenvolvimento desta derivada - encontra-se primeiramente a uniformização textual que se produz, ao mudar das línguas originais para uma única língua empregada pela coleção, de onde o ganho em facilidade de leitura funciona então como uma perda de complexidade. A uniformidade traz consigo a inevitável identificação das obras colecionadas, pois cada um dos livros se dilui, ou ao menos adquire novo significado, sob o título comum da série que de tal modo os identifica ${ }^{24}$. Essa característica do "efeito biblioteca" funciona ainda como o filtro que exclui, com a pecha potencial de irrelevância, aquelas obras que não mereceriam ser colecionadas. A inclusão se revela então como um terceiro plano onde se projeta o "efeito" e, com esta última perspectiva, as ausências literárias podem ser tão significativas quando as presenças. A inclusão permite, finalmente, que proceda uma expansão ou ampliação do

\footnotetext{
${ }^{22}$ Onde se encontram tratados escolásticos como Antonio Pérez ou Miguel Salón, mas também as obras de Tomás de Mercado, Suma de tratos y contratos, Luis de Alcalá, De los préstamos y otros contratos ou Pedro de Oñate, De contractibus.

${ }^{23}$ Há alguns anos tive a oportunidade de estudá-lo: cf. Petit (2007, p. 801-900, em especial p. 805 et seq.).

${ }^{24}$ Há não muito tempo me convidaram para colaborar na obra Great Christian Jurists in Spanish History (Cambridge Law and Christianity Book Series, ed. John Witte, Jr.) com uma biografia de Manuel Alonso Martínez (1827-1891). Se, no meu caso, a produção escrita do personagem permite atribuí-lo o adjetivo confessional - assim como o profissional, pois Alonso combinou sua dedicação política com sua vocação teórica -, há outros nomes previstos para os que, por sua vez, a catolicidade não aportaria nota específica alguma, para não referirmos àqueles outros - como o político Adolfo Suárez (1932-2014) - que somente poderíamos considerar juristas por estarem inseridos na obra referida.
} 
círculo dos eventuais leitores, pois a consulta de qualquer tomo da série seria a chave para ler os restantes.

\section{O TAMANHO DO DIREITO}

Seguramente um leitor experimentado possui a capacidade necessária para declinar outras consequências do chamado "efeito biblioteca", sempre externas ao conteúdo dos textos e, no entanto, geralmente convertidas em sutis condicionantes de sua substância. Todavia, biblioteca tem sido também, em uma fácil metonímia, o nome que recebe o catálogo ou inventário dos fundos de uma determinada coleção.

Por exemplo, em 1718 foi publicada em Hamburgo a Bibliothecae Kielmans-Eggianae Pars prima. Tratava-se de vender em leilão um grande jogo de livros e talvez isso explique que o critério principal de ordenação ali seguido fosse o tamanho dos volumes catalogados, divididos em seis seções, desde obras "In folio" (1-1511) até "Libri in Sedecimo" (1-154), com um pico que formam os "Libri in Octavo" (1-4873). As medidas variam de forma drástica: uma edição em grande fólio chega a alcançar meio metro de altura, enquanto que um pequeno dieciseisavo mede apenas 10 ou 12 centímetros. Deter-se nestas particularidades pareceria supérfluo, se não fosse porque a cruza do conteúdo dos livros com o elemento material de seu tamanho nos lança alguns resultados dignos de menção ${ }^{25}$.

Com efeito, realizei uma rápida indagação em torno dos termos ius (incluindo suas diversas formas: iure, iuris) e Recht, isto é, os dois vocábulos mais relevantes em uma velha livraria com títulos compostos principalmente em latim e em alemão.

Pois bem, a presença do direito entre os livros latinos utilizou preferencialmente o oitavo (18 títulos, uns $20 \mathrm{~cm}$ ), porém os in folio (seis títulos) e os tomos "in quarto" (sete [títulos], 25-30 cm) se encontram representados, sobretudo em relação ao isolado livro "in sedecimo". Esses sobem mais quando consideradas as obras alemãs (dez e oito peças), não obstante o gosto pelos formatos maiores para as obras jurídicas (sete in folio, 35 em quarto, 29 em oitavo) ainda se manter.

Quanto ao tamanho e à matéria, incluindo a índole do livro, as edições de fontes iuris tinham maior envergadura em correspondência com a dignidade de um texto; também culturalmente superior, a data de publicação haveria de ser adicionada para compreender as

\footnotetext{
${ }^{25}$ Um autor isolado recomendou distinguir os manuscritos jurídicos pela cor da encadernação, com argumentos para as diversas opções: Hespanha (2008, p. 13-14).
} 
modas ou estilos editoriais sem grandes desvios, ainda que estas linhas não pretendam improvisar em um vetor de trabalho que conta com seus próprios especialistas ${ }^{26}$. Somente se pretende chamar à atenção de quantos se dedicam a outras coisas sobre certas mudanças materiais que ilustram ou até respondem a transformações fundamentais na concepção do direito.

Em 1790, um Felipe de Cubero levou um alarmante memorial ao conde de Floridablanca, com propostas "para ocurrir en lo posible al gravísimo daño de que se propaguen en $\mathrm{N}$ [ues]tro Reyno los perniciosos escritos que con maligna fecundidad salen diariamente en los países vecinos", isto é, a França revolucionária ${ }^{27}$. Suas razões são agora do maior interesse, pois relacionam diretamente a toxicidade político-jurídica dos discursos e o aspecto exterior e a forma editorial das publicações:

[e]stà V.E. persuadido (y con razon) á que no son los libros de gran tamaño ni las obras de muchos volúmenes los enemigos terribles que oy mas nos ofenden: su precio, el tiempo y ocio que pide su comprehension y lectura los hacen accesibles á muy pocos, y esos son gente por lo comun que sabe preservarse del error, y aun quando le beba es entreverado con mucho y buena doctrina, pensamientos, erudicion, y eloquencia que suele hallarse en tales libros.

Pelo contrário, “o mal que convém atacar é o que causam as peças chamadas fugitivas: os espíritos de poucos olhos, entregues geralmente por espíritos fogosos, desenfreados sem religião, princípios ou pudor", posto que o panfleto - um texto de curto tamanho - "vende-se barato, lê-se logo, o compram todos".

Se diria que a serenidade política do Antigo Regime - estamentos, religião, hierarquias jurisdicionais - dependia do tamanho dos livros. A conclusão similar se chegará com um segundo documento, menos dramático por ser mais irônico, produzido nesse caso nos melhores ambientes do illuminismo italiano.

Fazemos referência à "Orazione panegirica sulla giurisprudenza milanese" (1763) do nobre Pietro Verri (1728-1797), amigo e mentor do jovem Cesare Beccaria. Aqui, Verri dá voz a um severo "Dottore della Biblioteca Ambrosiana" que lamentava, com toda forma de considerações e anedotas, a decadência injusta das tradições, referentes e modos de proceder do Senato, tribunal superior do Milanesado; uma leitura em filigrana revelaria que os falsos lamentos do doutor eram justamente o que Verri criticava. A "Orazione", baseada

\footnotetext{
${ }^{26}$ Assim, o escocês Douglas Osler, dedicado há anos à bibliografia jurídica; cf., por exemplo, Klostermann (2000); Klostermann (2009).

${ }^{27}$ Consulta-se o interessante documento no Archivo Histórico Nacional (Madrid), Consejos, leg. 11.278, $\mathrm{n}^{\circ} 94$.
} 
retoricamente na drástica oposição entre o velho e o novo em matéria de direito, declina várias dicotomias onde o aspecto do livro joga um papel dominante.

Uma de particular densidade contrapõe à "afetada jovenzinha" (uma "pettegola") o ancião "dottore" mencionado, onde a diferença de sexos se desliza como a implícita descrição de um "mundo ao revés" que replica as diferenças dos formatos literários:

[c]olla lettura di otto tometti d'un certo Voltaire conozco io una pettegola che ha osato far tacere un Dottore della Biblioteca Ambrosiana, il quale avendo studiara la storia su quarantanove Autori, tutti in foglio, cercava d'insegnarle qualche parte del suo sapere: si parlò del Concilio di Basilea, del Concilio di Costanza, e la Pettegola sapeva tutto... si parlò dei Templieri, e la Pettegola sapeva tutto, cosicchè il povero Dottore, fracido e logoro nella euridizione, non ha potuto dire nullo di nuovo ad una Signorina di venticinque anni che conserva intatto il vermeglio del suo volto.

História, política e religião comparecem às frases anteriores como âmbito material de uma controvérsia entre jovens e velhos, mulheres e homens, "tometti" e "in folios". Um segundo momento da "Orazione" entra em cheio no âmbito jurídico, mostrando-nos agora que as mudanças na forma dos livros tão visíveis no século XVIII eram, na verdade, a epifania de uma cultura jurídica diferente:

[o]rsù dicasi, Signori miei, delle vantate riforme del Re Federico di Prussia, il quale ha rovinato gli Stati suoi abolendo la Giurisprudenza Giustinianea, e sostituendo al Nuovo, al Vecchio, all'Inforziato, tre miserabili Tometti Tedeschi ai quali ha osato dare il nome di Codice, ridicolo Codice invero che potrebbe portarsi comodamente al passeggio!

\section{O TEMPO E OS TEXTOS}

O código legal - metáfora da experiência jurídica contemporânea - viu-se acompanhado por uma nova espécie de textos que acompanha até hoje essa experiência. Refiro-me às revistas: uma forma literária de produção periódica de textos breves e seriados, nascida com a Ilustração, causa e efeito - ao mesmo tempo - da opinião pública.

Dotadas em sua origem de conteúdos inespecíficos, próprio de uma transbordante erudição de corte cosmopolita, as revistas rapidamente se orientaram à especialização. Não foi o saber jurídico um dos mais atrasados. Que o manifesto de Friedrich Karl von Savigny, ao lançar em 1815 - um ano depois de sua cética crítica às ideias sobre a codificação do direito - 
a Zeitschrift für geschichtliche Rechtswissenschaft (1815), seja um texto conhecido, não nos livra de recordar algumas de suas afirmações ${ }^{28}$. Ao menos esta:

[a] forma de revista que adotamos requer algum especial esclarecimento... Semelhantes formas, passageiras e transitórias, da literatura, não parecem gozar agora na Alemanha daquela extraordinária aceitação de que não faz muito desfrutavam... O que em realidade se considera digno de estima é o desenvolvimento do pensamento nas sólidas formas de um grande conjunto, ou seja, o que ordinariamente chamamos livros.

Porém: ao oferecer as revistas ocasião frequente de comunicar os pensamentos ainda não elaborados e somente como em esboço, o qual sempre é mais cômodo, dificultam em certo modo que se publiquem boas obras completas e, neste sentido, poderia qualificá-las com razão de um estorvo para a formação dos livros. Não obstante isso, usadas de uma maneira prudente, podem produzir efeitos benéficos. A passagem do estado de ideias isoladas aos completos e bons livros verifica-se sucessivamente e é, ademais, muito lenta no mais das vezes. Se uma revista aspira a facilitar e promover dito processo, pode produzir muito úteis resultados... A literatura de uma nação não se dá nem permanecendo imóvel, nem se manifestando parcial e exclusivamente em livros e autores isolados; antes pelo contrário, produzse e se anima continuamente pelos sábios todos, em comunidade e mútua ação e reação com o público, e creio que qualquer pessoa prática nestas questões se aperceberá facilmente disso, ainda ali onde se oferece uma maior dificuldade, a saber, na época presente e em nossa própria nação.

A citação peca pelo comprimento, mas resulta imprescindível por plasmar com eficácia a novidade que introduziu no direito esta classe, igualmente nova, de texto jurídico. A revista tornou possível, em primeiro lugar, ajustar o tempo da cultura e o tempo da norma: frente àquele altes, gutes Recht característico do Medievo, a política liberal o fez depender da vontade histórica do Estado - os parlamentos, mas sobretudo os governos -, que baseavam sua capacidade legiferante no controle de uma gazeta ou de um boletim oficial ${ }^{29}$. Porém, o direito, em segundo lugar, graças a Savigny e sua escola, afirmou-se em seguida como uma

\footnotetext{
28 "La forma de revista que hemos adoptado, requiere alguna especial aclaración... Semejantes formas, pasajeras y transitorias, de la literatura, no parecen gozar ahora en Alemania de aquella extraordinaria aceptación de que no ha mucho disfrutaban... Lo que en realidad se considera digno de estima es el desarrollo del pensamiento en las sólidas formas de un gran conjunto, es decir, lo que ordinariamente llamamos libros. Ahora bien: al ofrecer las revistas ocasión frecuente de comunicar los pensamientos aún no elaborados y solo como en bosquejo, lo cual siempre es más cómodo, dificultan en cierto modo el que se publiquen buenas obras completas, y en este sentido podría calificárselas con razón de un estorbo para la formación de los libros. No obstante, usadas de una manera prudente pueden producir efectos beneficiosos. El paso del estado de ideas aisladas a los completos y buenos libros, se verifica sucesivamente y es, por tanto, muy lento las más de las veces. Si una revista aspira a facilitar y promover dicho proceso, puede producir muy útiles resultados... La literatura de una nación no se da ni permaneciendo inmóvil, ni manifestándose parcial y exclusivamente en libros y autores aislados; antes al contrario, se produce y anima continuamente por los sabios todos en comunidad y mutua acción y reacción con el público, y creo que cualquier persona práctica en estas cuestiones se apercibirá fácilmente de ello, aun allí donde se ofrece una mayor dificultad, a saber, en la época presente y en nuestra propia nación" [n. trad. - na publicação original do texto, Carlos Petit utilizou versão em espanhol]. Aqui se utiliza, por comodidade, a tradução de R. Atard (1908), reproduzida por Casanovas y Moreso (1994, p. 22-31).

${ }^{29}$ Cf. Kern (2013). Serrano González desenvolveu a questão em nossas terras (In: Tau Anzoátegui, 1997, p. 77 109).
} 
disciplina de natureza científica: até na seleção dos termos, com esses célebres juristas se produziu o grande salto da velha Jurisprudenz à moderna Rechtswissenschaft. E então, a potência da revista como espaço ideal de encontro e discussão serviu para organizar - por dizer a la Savigny - "todos os sábios em comunidade". Assim, estabelecido o momento comunicativo da ciência do direito, a revista pode servir, em terceiro lugar, como banco de provas de hipóteses e de teorias que somente através de um sério debate mereceriam a pena de precipitar como publicação autônoma:

\begin{abstract}
Un elemento nuevo, peculiar de la civilización moderna, el periodismo, ha venido también a sumar su influencia vivificadora. Signo espontáneo de nuestra época, á todo se ha lanzado, todo lo ha invadido, sobre todo ha llamado la atención jeneral. El periodismo es la primera necesidad moral de este tiempo: es el vapor y el camino de hierro de la intelijencia: es el gran vehículo y la gran palanca de la común actividad que nos devora. No pidais libros á la jeneración presente: el periodismo los ha matado, como la imprenta mató á la escritura de los siglos anteriores. El primero que publicó un Diario, fué el continuador de Guttemberg.
\end{abstract}

Essas frases, obra do advogado e publicista Joaquín Francisco Pacheco ${ }^{30}$, nem sequer admitiam o horizonte longínquo de um livro previamente ensaiado nas revistas ${ }^{31}$. Deslizadas em uma publicação pioneira no âmbito do direito, documentam uma mudança na categoria dos textos em que a forma periódica e a substância jurídica vêm reciprocamente implicadas. Esta segunda requeria imprimir no ordenamento - sob a consigna do que chamaríamos de "filosofia jurídica da vigência normativa" - os ritmos de mudança e de transformação que somente aquela primeira poderia nos assegurar.

Contudo, esse "derecho por entregas" contido nas revistas impõe certas regras de leitura que se vinculam às características especiais dessa sorte de textos ${ }^{32}$. Um estudo anterior desenvolvido sobre a fugaz, porém admirável, publicação intitulada La Escuela del Derecho (1863-1865) mostrou as notáveis diferenças que existem entre a consulta a uma coleção encadernada e a uma que não o está - uma operação aparentemente tão alheia ao conteúdo como a tarefa mecânica de encadernar uns fascículos altera completamente a qualidade textual.

A comum redução à condição de volume anual oculta a vivacidade de uma revista que poderia ter uma cadência mensal. Ademais, o encadernador sacrifica a capa do fascículo e certos elementos efêmeros (folhetos descartáveis, listas de assinantes, anúncios de trabalhos

\footnotetext{
${ }^{30}$ Quem, a respeito do seu trabalho com a imprensa jurídica, foi Savigny: cf. Pacheco (1836, p. 02).

${ }^{31}$ E alguns dos livros de Pacheco, como suas famosas lições de direito penal (1842) ou de direito político (1845), nasceram - como tantos outros - de anotações de aula.

${ }^{32}$ Para o que segue, Petit (In: Merchán; Pinard, 1998, p. 533-584).
} 
futuros, obsequio de monografias por entregas). No caso de La Escuela, sabemos por um exemplar não-encadernado que o fascículo de outubro de 1863 “(...) ha salido con gran retraso con motivo del Congreso de Jurisconsultos, cuyas actas habíamos desde luego pensado publicar". O terceiro número de 1865 (março desse ano, segundo o caráter mensal que anunciou La Escuela?) avisava que "despues de tiradas y repartidos parte de los números $1^{\circ}$ y $2^{\circ}$ del tomo $7^{\circ}$ de la Revista, fué preciso proceder á una nueva impresión de algunos pliegos en que se habian cometido varias faltas tipográficas. Este ha sido el motivo de haber recibido muchos Sres. suscritores los números citados con un estraordinario retraso".

Mas também foi a razão de uma rareza bibliográfica:

una insólita reseña de "Bachofeu [sic], Das Miterrecht [sic] ... (el derecho de la madre), investigaciones sobre la gynecocracia del mundo antiguo, considerada bajo el punto de vista de la religion y del derecho, por M. Bachefeu [sic], consejero del Tribunal de apelación de Bâle; 1 tomo en $4^{\circ}$. Stuttgard [sic], Krais et Hoffmann, 1861.

que hoje é trabalhosa de se encontrar; na coleção utilizada - presente na Biblioteca de Humanidades da Universidade de Sevilha - encontram-se quatro páginas enviadas aos assinantes para corrigir o erro de paginação. A capa do fascículo anunciou a aparição de um artigo que foi no final suprimido (por problemas de censura?), sem a qual nada saberíamos de tais dificuldades editoriais.

Escrita, formato, tamanho, temporalidade... através desse breve recorrido, poderemos duvidar da estreita relação que intermedia a forma e a substância dos textos jurídicos?

\section{REFERÊNCIAS}

ACCARISTI, M.; BELLOTI, M. Abitare la biblioteca: Arredo e organizzazione degli spazi nella biblioteca pubblica. Roma: Oberon, 1984.

Archivo Histórico Nacional (Madrid), Consejos, leg. 11.278, n. ${ }^{\circ} 94$.

CASANOVAS, P.; MORESO, J. (Eds.). El ámbito de lo jurídico. Lecturas de pensamiento jurídico contemporáneo. Barcelona: Crítica, 1994.

CHARTIER, R. Bibliothèques sans murs. In: Culture écrite et société: L'ordre des livres (XIVe-XVIIIe siècles). Paris: Albin Michel, 1996.

CORTESE, E. La norma giuridica: Spunti sul tema nel diritto comune classico I. Milano: Giuffrè, 1964 (rist. 1995). 
DOLEZALEK, G. Scriptura non est de substantia legis: A propos d'une décision de la Rote Romaine, de l'an 1378 environ. In: Diritto comune e diritti locale nella storia dell'Europa. Milano: Giuffrè, 1980.

D’ORS, A. Titulus. Anuario de Historia del Derecho Español, v. 23, p. 495-514, 1953.

EINSENSTEIN, E. The Printing Press as an Agent of Change, I-II. Cambridge: Cambridge University Press, 1980.

GALLEGO ANABITARTE, A. Formación y enseñanza del derecho público en España (1769-2000): Un ensayo crítico. Madrid: Marcial Pons, 2002.

HESPANHA, António Manuel. Form and Content in Early Modern Legal Books: Bridging the Gap between Material Bibliography and the History of Legal Thought. Rechtsgeschichte, v. 12, 12-50, 2008.

JOHANOTT, Y. Tourner la page: Livre, rites et symboles. 2ª ed. Grenoble: J. Millon, 1994.

KASER, M. Römische Rechstgeschichte. Göttingen: Vandenhoeck \& Ruprecht, 1967.

KERN, F. Derecho y Constitución en la Edad Media. Trad., notas e estudo introdutório por Faustino Martínez. Valencia: Kyrios, 2013.

LASO, E. Elementos del derecho mercantil de España, formados con arreglo al programa de tercer año de Jurisprudencia. Madrid: Lib. Calleja, 1849.

LASO, E. Ensayo de Jurisprudencia mercantil, que dedica á sus amados Discípulos el Profesor de 3er. año en la Universidad de Madrid [1847], ms. conservado en la Biblioteca Nacional (Madrid), signatura 5662, 1847.

MITTEIS, L.; LEVY, E.; RABEL, E. (Eds.). Index interpolationum quae in Iustiniani Digestis inesse dicuntur, I-III. Weimar: Hermann Böhlaus Nachfolger, 1929-1935.

OSLER, D. Catalogue of books printed in Spain, Portugal and the Southern and Northern Netherlands from the beginning of printing to 1800 in the Max-Planck-Institut für Europäische Rechtsgeschichte. Frankfurt/Main: Vittorio Klostermann, 2000.

OSLER, D. (comp.). Jurisprudence of the Baroque: A Census of Seventeenth Century Italian Legal Imprints - [I:] A-G, [II:] H-S, [III:] T-Z, Sources. Frankfurt am Main: Vittorio Klostermann, 2009.

PACHECO, J. Prospecto. Boletín de Jurisprudencia y Legislación, v. 1, p. 01-06, 1836.

PALAZZINI FINETTI, L. Storia della ricerca delle interpolazioni nel Corpus iuris giustinianeo. Milano: Giuffrè, 1953. 
PETIT, C. La Administración y el Doctorado: centralidad de Madrid. Anuario de Historia del Derecho Español, v. 67, p. 593-614, 1997.

PETIT, C. La Escuela del derecho (1863-1865). Empeño de ciencia jurídica en la España isabelina. In: MERCHÁN, A.; PINARD, G. E. (eds.). Libro homenaje: In memoriam Carlos Díaz Rementería. Huelva: Servicio de Publicaciones, p. 533-584, 1998.

PETIT, C. Lombroso en Chicago. Presencias europeas en la "Modern Criminal Science" americana. Quaderni fiorentini per la storia del pensiero giuridico moderno, v. 36, p. 801900, 2007.

PETIT, C. Discurso sobre el discurso: Oralidad y escritura en la cultura jurídica liberal. $2^{\mathrm{a}}$ ed. Madrid: Universidad Carlos III de Madrid, 2014.

HESPANHA, António Manuel. Southern Europe (Italy, Iberian Peninsula, France). In: PIHLAJAMÄKI, H.; DUBBER, M.; GODFREY, M. (eds.). Oxford Handbook of European Legal History. Oxford: Oxford University Press, 2018.

SAURI Y LLEOPART, R. Elocuencia forense. Barcelona: Herederos Vda. de Pla, 1847.

SERRANO, A. Revistas jurídicas en España: una cuestión de estilo. In: TAU ANZOÁTEGUI, Víctor (ed.). La revista jurídica en la cultura contemporánea. Buenos Aires: Ediciones Ciudad Argentina, 1997.

SOETERMEER, F. Utrumque ius in peciis: Aspetti della produzione libraria a Bologna fra Due e Trecento. Milano: Giuffrè, 1997.

VALLEJO, J. Ruda equidad, ley consumada: Concepción de la potestad normativa (12501350). Madrid: Centro de Estudios Constitucionales, 1992.

VANO, C. Il nostro autentico Gaio: Strategie della Scuola Storica alle origini della romanistica moderna. Napoli: Editoriale Scientifica, 2000.

\section{DADOS DA PUBLICAÇÃO}

Categoria: autor convidado

Recebido em: 20/08/2021

Aceito em: 24/08/2021 